\title{
Delayed Mitochondrial Dysfunction in Excitotoxic Neuron Death: Cytochrome c Release and a Secondary Increase in Superoxide Production
}

\author{
C. Marc Luetjens, ${ }^{1}$ Nguyen Truc Bui, ${ }^{1}$ Bernd Sengpiel, ${ }^{3}$ Gudrun Münstermann, ${ }^{1}$ Monika Poppe, ${ }^{1}$ \\ Aaron J. Krohn, ${ }^{1}$ Elke Bauerbach, ${ }^{3}$ Josef Krieglstein, ${ }^{3}$ and Jochen H. M. Prehn ${ }^{1,2,3}$ \\ 1/nterdisciplinary Center for Clinical Research, Research Group "Apoptosis and Cell Death" and 2Department of \\ Pharmacology and Toxicology, Westphalian Wilhelms-University, D-48149 Münster, and "3Department of Pharmacology and \\ Toxicology, Philipps-University, D-35032 Marburg, Germany
}

\begin{abstract}
An increased production of superoxide has been shown to mediate glutamate-induced neuron death. We monitored intracellular superoxide production of hippocampal neurons during and after exposure to the glutamate receptor agonist NMDA (300 $\mu \mathrm{M})$. During a 30 min NMDA exposure, intracellular superoxide production increased significantly and remained elevated for several hours after wash-out of NMDA. After a 5 min exposure, superoxide production remained elevated for $10 \mathrm{~min}$, but then rapidly returned to baseline. Mitochondrial membrane potential also recovered after wash-out of NMDA. However, recovery of mitochondria was transient and followed by delayed mitochondrial depolarization, loss of cytochrome $c$, and a secondary rise in superoxide production 4-8 hr after NMDA exposure. Treatment with a superoxide dismutase mimetic before the secondary rise conferred the same protection against cell death as a treatment before the first. The secondary rise could be inhibited by the
\end{abstract}

complex I inhibitor rotenone (in combination with oligomycin) and mimicked by the complex III inhibitor antimycin A. To investigate the relationship between cytochrome $c$ release and superoxide production, human D283 medulloblastoma cells deficient in mitochondrial respiration ( $\rho^{-}$cells) were exposed to the apoptosisinducing agent staurosporine. Treatment with staurosporine induced mitochondrial release of cytochrome $c$, caspase activation, and cell death in control and $\rho^{-}$cells. However, a delayed increase in superoxide production was only observed in control cells. Our data suggest that the delayed superoxide production in excitotoxicity and apoptosis occurs secondary to a defect in mitochondrial electron transport and that mitochondrial cytochrome $c$ release occurs upstream of this defect.

Key words: excitotoxicity; glutamate; NMDA; mitochondria; reactive oxygen species; superoxide; cytochrome c; respiratory chain; apoptosis
Overactivation of glutamate receptors is responsible for excitotoxic neuron death after trauma, epileptic seizures, and cerebral ischemia (Choi, 1994). In most experimental and clinical settings, glutamate toxicity is mediated through activation of $\mathrm{Ca}^{2+}$ permeable NMDA receptors (Choi, 1994). Reduction of $\mathrm{Ca}^{2+}$ influx or intracellular $\mathrm{Ca}^{2+}$ chelation has been shown to prevent this process, suggesting that NMDA receptor-mediated cell death is triggered by neuronal $\mathrm{Ca}^{2+}$ overloading (Choi, 1987; Tymianski et al., 1993). However, the importance of the diverse events downstream of neuronal $\mathrm{Ca}^{2+}$ overloading is still controversial. $\mathrm{Ca}^{2+}$-induced nitric oxide production and activation of calpains have been shown to contribute to excitotoxic neurodegeneration (Siman et al., 1989; Dawson et al., 1991). Mitochondria have been shown to take up large amounts of $\mathrm{Ca}^{2+}$ during exposure to excitotoxins (White and Reynolds, 1995; Budd and Nicholls, 1996a,b; Peng and Greenamyre, 1998). This was initially believed to be a $\mathrm{Ca}^{2+}$-buffering mechanism that protects against "toxic" increases in cytosolic $\mathrm{Ca}^{2+}$ concentration. However, there is now considerable data suggesting that mitochondrial $\mathrm{Ca}^{2+}$ uptake is in fact necessary to trigger excitotoxic neuron death (Budd and Nicholls, 1996a,b; Castilho et al., 1998; Stout et al., 1998).

Mitochondrial $\mathrm{Ca}^{2+}$ overloading may activate neuronal cell death by at least three known mechanisms: (1) energy depletion,

\footnotetext{
Received Feb. 22, 2000; revised May 4, 2000; accepted May 9, 2000.

This work was supported by Interdisciplinary Center for Clinical Research (IZKF), Universität Münster (Bundesministerium für Bildung, Wissenschaft, Forschung und Technologie Grant 01 KS 9604/0) and DFG (Pr 338/9-1 and Forschergruppe "Neuroprotektion"). We thank Christiane Schettler for technical assistance.

C.M.L. and N.T.B. contributed equally to this work.

Correspondence should be addressed to Dr. Jochen H. M. Prehn, Interdisciplinary Center for Clinical Research (IZKF), Research Group "Apoptosis and Cell Death," Faculty of Medicine, Westphalian Wilhelms-University, Röntgenstrasse 21, D-48149 Münster, Germany. E-mail: prehn@uni-muenster.de.

Copyright (C) 2000 Society for Neuroscience $0270-6474 / 00 / 205715-09 \$ 15.00 / 0$
}

(2) release of pro-apoptotic factors, and (3) increased generation of reactive oxygen species (ROS). Energy depletion occurs when glutamate receptors are overactivated for a longer period of time and leads to a severe disturbance of neuronal ion homeostasis and, eventually, necrotic cell death (Ankarcrona et al., 1995). However, transient glutamate receptor overactivation, which is more likely to occur in acute neurological disorders, may lead to a recovery of the mitochondrial energetics and a delayed, apoptotic cell death (Ankarcrona et al., 1995). Mitochondrial $\mathrm{Ca}^{2+}$ overloading may trigger neuronal apoptosis via the release of pro-apoptotic factors from the mitochondrial intermembrane space into the cytosol (Liu et al., 1996; Andreyev et al., 1998). Release of cytochrome $c$, in particular, is able to activate a family of cysteine proteases, the caspases, which are required for most of the biochemical and morphological changes leading to apoptosis ( $\mathrm{Li}$ et al., 1997). Finally $\mathrm{Ca}^{2+}$ induced mitochondrial dysfunction can lead to an increased production of ROS, in particular superoxide (Malis and Bonventre, 1985; Dykens, 1994). Indeed, it has been shown that mitochondria generate superoxide and related ROS during glutamate receptor overactivation (Lafon-Cazal et al., 1993; Dugan et al., 1995; Reynolds and Hastings, 1995; Bindokas et al., 1996; Patel et al., 1996) and that inhibition of superoxide formation reduces excitotoxic neuron death (Chan et al., 1990; Patel et al., 1996). In light of the increasing evidence that mitochondria are able to initiate excitotoxic and apoptotic neuron death, we investigated the role of mitochondrial superoxide production and cytochrome $c$ release in NMDA neurotoxicity and apoptosis.

\section{MATERIALS AND METHODS}

Materials. Antimycin A, NMDA, oligomycin, paraquat, rotenone, and staurosporine were from Sigma (Deisenhofen, Germany). Hydroethidine (HEt) and rhodamine-123 (R-123) were from Molecular Probes (Leiden, The Netherlands). The cell-permeable superoxide dismutase (SOD), mimetic manganese tetrakis (4-benzoyl acid), porphyrin (MnTBP) (Patel 
and Day, 1999), and the caspase substrate acetyl-DEVD-7-amido-4methylcoumarin (Ac-DEVD-AMC) were purchased from Alexis (Grünstetten, Germany). Dizocilpine and tetrodotoxin were from RBI Biotrend (Cologne, Germany). All other chemicals came in analytical grade purity from Merck (Darmstadt, Germany).

Hippocampal neuron culture. Cultured hippocampal neurons were prepared from neonatal [postnatal day 1 (P1)] Fischer 344 rats as described (Krohn et al., 1998). Dissociated hippocampal neurons were plated at a density of $2 \times 10^{5}$ cells/ $/ \mathrm{cm}^{2}$ onto poly-L-lysine-coated glass coverslips that were placed into $35 \mathrm{~mm}$ Petri dishes. For cytotoxicity assays, cells were plated onto poly-D-lysine-coated 24-well plates (Nunc, Wiesbaden, Germany). Cells were maintained in MEM medium supplemented with $10 \%$ NU-serum, $2 \%$ B-27 supplement $(50 \times$ concentrate) $), 2$ mM L-glutamine, 20 $\mathrm{mm}$ D-glucose, $26.2 \mathrm{~mm}$ sodium bicarbonate, $100 \mathrm{U} / \mathrm{ml}$ penicillin, and 100 $\mu \mathrm{g} / \mathrm{ml}$ streptomycin (Life Technologies, Karlsruhe, Germany). All experiments were performed on 14- or 15-d-old cultures. Animal care followed official governmental guidelines.

Generation and maintenance of human medulloblastoma D283 cells deficient in mitochondrial respiration. D283 cells originate from a human cerebellar medulloblastoma and are positive for neurofibrillary proteins, glutamine synthetase, MAP2, and neuron-specific enolase, but negative for glial fibrillary acidic protein and S-100 protein (Vinores et al., 1994). Human medulloblastoma D283 cells deficient in mitochondrial respiration ( $\rho^{-}$cells) were generated by selective elimination of mitochondrial DNA (mtDNA) (M. Poppe, G. Münstermann, and J. H. M. Prehn, unpublished observations). Cells were exposed for 8 weeks to ethidium (Et) bromide $(0.5 \mu \mathrm{g} / \mathrm{ml}$; Sigma $)$ in RMPI 1460 medium supplemented with glucose $(4.5$ $\mathrm{mg} / \mathrm{ml})$, sodium pyruvate $(0.1 \mathrm{mg} / \mathrm{ml})$, and uridine $(50 \mu \mathrm{g} / \mathrm{ml})(\mathrm{King}$ and Attardi, 1989), as well as penicillin $(100 \mathrm{U} / \mathrm{ml})$, streptomycin $(100 \mu \mathrm{g} / \mathrm{ml})$, and $10 \%$ fetal calf serum (Life Technologies). Reduction of mtDNA content by a controlled Et bromide treatment leads to selective, voltagedriven uptake of Et into mitochondria, intercalation into mtDNA, and inhibition of mtDNA replication. mtDNA encodes subunits of mitochondrial complexes I, III, and IV that are required for mitochondrial respiration. Because the oxidative phosphorylation system in these cells is severely inhibited, cell growth depends on the presence of glucose and pyruvate as key components. D283 $\rho^{-}$cells maintained growth but exhibited a significant reduction in mtDNA-encoded proteins (see Fig. 8a). Withdrawal of pyruvate from the culture medium led to a rapid cell death of $\rho^{-}$cells, in contrast to control cells. Moreover, assessment of cytochrome $c$ oxidase (complex IV) activity according to Vaillant and Nagley (1995) indicated that mitochondrial respiratory activity of $\rho^{-}$cells was significantly reduced, whereas complex II activity was unaltered compared with controls (Poppe, Münstermann, and Prehn, unpublished observations). Mitochondrial complex II (succinate dehydrogenase) contains only nucleus-encoded subunits. Exposure to rotenone, an inhibitor of complex I, induced significant cell death in control cultures, whereas $\rho^{-}$cells were resistant even to high concentrations of this inhibitor (see Fig. 8b). Similar results were obtained after exposure to the complex III inhibitor antimycin A $(0.01-1 \mu \mathrm{M})$.

Induction of excitotoxic neuronal injury. Cultures were washed in HEPES-buffered saline (HBS) containing (in mM: $144 \mathrm{NaCl}, 10 \mathrm{HEPES}$, $2 \mathrm{CaCl}_{2}, 1 \mathrm{MgCl}_{2}, 5 \mathrm{KCl}, 10$ D-glucose (320 mOsm, pH 7.4) and were then exposed for $5 \mathrm{~min}$ (brief exposure) or $30 \mathrm{~min}$ (prolonged exposure) to $\mathrm{Mg}^{2+}$-free HBS supplemented with $300 \mu \mathrm{M}$ NMDA, 0.5 $\mu \mathrm{M}$ tetrodotoxin, and $100 \mathrm{~nm}$ glycine (Sengpiel et al., 1998). Control cultures were exposed to $\mathrm{Mg}^{2+}$-free HBS devoid of NMDA (sham exposure). After the exposure, cells were washed and returned to the original culture medium. Cell death was determined with trypan-blue uptake $(0.5 \%$ in HBS, $5 \mathrm{~min})$, which identifies membrane leakage, the endpoint of neuronal degeneration. A total number of $400-500$ neurons were counted in three to four subfields of each culture. Cell counts were performed by two investigators without knowledge of the respective treatments, and the mean of the two results was used for statistical analysis.

Induction of apoptotic injury and assessment of caspase activity. Control and $\rho^{-}$D283 cells were exposed to the apoptosis-inducing protein kinase inhibitor staurosporine (3 $\mu \mathrm{M})$ as described (Falcieri et al., 1993; Krohn et al., 1998). For caspase activity experiments, cells were lysed in $200 \mu \mathrm{l}$ of lysis buffer [10 mM HEPES, $\mathrm{pH} 7.4,42 \mathrm{mM} \mathrm{KCl}, 5 \mathrm{~mm} \mathrm{MgCl}, 1 \mathrm{~mm}$ phenylmethylsulfonyl fluoride, $0.1 \mathrm{~mm}$ EDTA, $0.1 \mathrm{~mm}$ EGTA, $1 \mathrm{~mm}$ dithiothreitol, $1 \mu \mathrm{g} / \mathrm{ml}$ pepstatin A, $1 \mu \mathrm{g} / \mathrm{ml}$ leupeptin, $5 \mu \mathrm{g} / \mathrm{ml}$ aprotinin, $0.5 \% 3$-(3-cholamidopropyldimethyl-ammonio)-1-propane sulfonate]. Fifty microliters of this extract were added to $150 \mu \mathrm{l}$ of reaction buffer [25 mM HEPES, 1 mM EDTA, $0.1 \%$ 3-(3-cholamidopropyldimethylammonio)1-propane sulfonate, $10 \%$ sucrose, $3 \mathrm{~mm}$ dithiothreitol, $\mathrm{pH}$ 7.5] (Krohn et al., 1998). The reaction buffer was supplemented with $10 \mu \mathrm{M}$ Ac-DEVDAMC, a fluorogenic substrate preferentially cleaved by caspase- $3,-7$, and -8 , but also caspase- $-1,-6,-9$, and -10 . Production of fluorescent AMC was monitored over $60 \mathrm{~min}$ using a fluorescent plate reader (HTS 7000, Perkin-Elmer, Langen, Germany) (excitation $380 \mathrm{~nm}$, emission $460 \mathrm{~nm}$ ). Fluorescence of blanks containing no cellular extracts was substracted from the values. Protein content was determined using the Pierce Coomassie Plus Protein Assay reagent (KMF, Cologne, Germany), and the caspase activity is expressed as change in fluorescent units per hour per microgram of protein.

HEt-based detection of intracellular superoxide production. Superoxide production of the hippocampal neurons was monitored by digital video microscopy using the probe HEt (Bindokas et al., 1996). HEt is taken up by living cells and oxidized by superoxide to its fluorescent product, Et. Et is retained intracellularly by stably binding to DNA and RNA. Digital video microscopy was conducted as described (Sengpiel et al., 1998) using a fluorescence microscope (Axiovert 100 inverted-stage microscope, Zeiss). Optics were as follows: excitation of $490 \mathrm{~nm}$, dichroic mirror of 505 $\mathrm{nm}$, and emission $>510 \mathrm{~nm}$. Images were collected using a $40 \times$ fluorescence objective and an intensified CCD camera (C 2400-87, Hamamatsu, Herrsching, Germany). Sixteen frames were averaged every $20 \mathrm{sec}$. Images were digitized as $256 \times 256$ pixels. Before every experiment, a background image was taken that was later substracted from the images. Data were analyzed using Argus-50 software (Hamamatsu). HEt $(2 \mu \mathrm{g} / \mathrm{ml})$ was present in the extracellular solution during the entire experiment. The extracellular solution was exchanged every $5 \mathrm{~min}$ by a fresh solution. In the experiment shown in Figure 7, Et fluorescence was acquired using a 12-bit digital CCD camera (Visicam Visitron) and analyzed using Metamorph software (Universal Imaging Corporation, West Chester, PA). Experiments were conducted at room temperature.

Under conditions of mitochondrial depolarization and prolonged $\mathrm{HEt}$ exposure, mitochondrially generated Et may be released into the cytoplasm, resulting in an artificial fluorescence enhancement (Castilho et al., 1999). We therefore additionally quantified Et fluorescence of hippocampal neuron cultures after homogenizing the cells in lysis buffer (10\% SDS, $0.1 \mathrm{M}$ Tris, $\mathrm{pH} 7.5)$. Et fluorescence of cell lysates was quantified using a fluorescence plate reader (FL 500, Biotek; excitation $485 \mathrm{~nm}$, emission 530 $\mathrm{nm}$ ). Lysis buffer served as blanks. Protein content was determined using the Pierce BCA Micro Protein Assay kit (KMF), and Et fluorescence of cell lysates was expressed as fluorescence units per microgram of protein. $R$-123-based estimation of mitochondrial membrane potential $(\Delta \Psi \mathrm{\Psi})$. $\mathrm{R}-123$ is a cationic, lipophilic dye that accumulates in the negatively charged mitochondrial matrix according to the Nernst equation potential (Emaus et al., 1986; Ehrenberg et al., 1988). An R-123 stock was prepared at a concentration of $1 \mathrm{mg} / \mathrm{ml}$ in DMSO and stored at $-20^{\circ} \mathrm{C}$. Working $\Delta \Psi_{\mathrm{m}}$ during the NMDA exposure, cells were incubated with $30 \mathrm{nM}$ R-123 for $15 \mathrm{~min}$ in culture medium and were then exposed for $5 \mathrm{~min}$ to NMDA $(300 \mu \mathrm{M})$ or $\mathrm{Mg}^{2+}$-free HBS (sham). For the estimation of $\Delta \Psi_{\mathrm{m}} 2$ and $6 \mathrm{hr}$ after the NMDA exposure, cells were exposed to NMDA or $\mathrm{Mg}^{2+}$-free HBS (sham) for $5 \mathrm{~min}$ and returned to the original culture medium. After 2 or 6 hr, cells were loaded with $30 \mathrm{nM} \mathrm{R}-123$ for $15 \mathrm{~min}$ in culture medium, and fluorescence was acquired. R-123 fluorescence was measured using an inverted Olympus IX70 microscope attached to a confocal laser scanning unit equipped with a $488 \mathrm{~nm}$ argon laser and a $20 \times$ fluorescence objective (Fluoview; Olympus, Hamburg, Germany). The dye was present in the extracellular solution during the entire course of the data collection. The regions of interest were monitored and focused by eye and then scanned once. Neurons were recognized by morphology as well as by their position in a higher plane than astrocytes. We obtained two images per scan: a transmission and a confocal fluorescence image. Data were analyzed using Metmorph software. Fluorescence data are given as the ratio between the average pixel intensity of the neuronal soma and the nucleus according to Wadia et al. (1998) to compensate for background differences and unequal $\mathrm{R}-123$ loading.

Cytochemical detection of intracellular superoxide production. Intracellular superoxide production was cytochemically detected using the 3,3'diaminobenzidine (DAB)/Mn method in which DAB is oxidized by $\mathrm{Mn}^{3+}$ derived from $\mathrm{Mn}^{2+}$ on oxidation by superoxide (Briggs et al., 1986). Hippocampal neurons were incubated for $60 \mathrm{~min}$ at $37^{\circ} \mathrm{C}$ in HBS supplemented with $2.5 \mathrm{~mm} \mathrm{DAB}, 0.5 \mathrm{~mm} \mathrm{MnCl}_{2}$ and $1 \mathrm{~mm} \mathrm{NaN}_{3}$ in the presence or absence of mitochondrial respiratory chain inhibitors and in the presence of $1 \mu \mathrm{M}$ dizocilpine. The cytochemical reaction was terminated by fixing the cells. Neurons with brown precipitates were considered positive and quantified by cell counting as described above.

Immunofluorescence microscopy and labeling of mitochondria. After exposure to NMDA, hippocampal neurons or D283 cells were washed, fixed and permeabilized. The primary antibody (mouse monoclonal anticytochrome $c, 6 \mathrm{H} 2 . \mathrm{B} 4$; PharMingen, San Diego, CA) was then added at a concentration of $10 \mu \mathrm{g} / \mathrm{ml}$ for $2 \mathrm{hr}$ at room temperature in blocking buffer. After washing, Cy3-conjugated anti-mouse IgG (1:1000, Jackson Immunoresearch Laboratories, West Grove, PA) was added for $1 \mathrm{hr}$. Mitochondria were labeled using the potential-insensitive probe Mitotracker Green FM (200 nM) (Molecular Probes) before fixation as described previously (Krohn et al., 1999). In another set of experiments, mitochondria were labeled using a rabbit polyclonal anti-SOD-2 antibody (StressGene, Victoria, Canada) raised against rat SOD-2 diluted 1:300. Fluorescence was observed using an Eclipse TE300 inverted microscope (Nikon, Düsseldorf, Germany). Digital images of equal exposure were acquired using a SPOT-2 digital camera (Diagnostic Instruments, Sterling Heights, MI) and Metamorph software. Cytochrome $c$ immunofluorescence of D283 cells was observed by confocal laser scanning microscopy as described above.

$S D S-P A G E$ and Western blotting. D283 cells were rinsed with ice-cold PBS and lysed in Tris-buffered saline containing SDS, glycerin, and protease inhibitors. Protein content was determined using the Pierce BCA Micro Protein Assay kit, and samples were supplemented with 2-mercaptoethanol and denaturated at $95^{\circ} \mathrm{C}$ for $5 \mathrm{~min}$. An equal amount of protein $(20 \mu \mathrm{g})$ was separated with SDS-PAGE and blotted to nitrocellulose membranes (Protean BA 85; Schleicher \& Schuell, Dassel, Germany). 


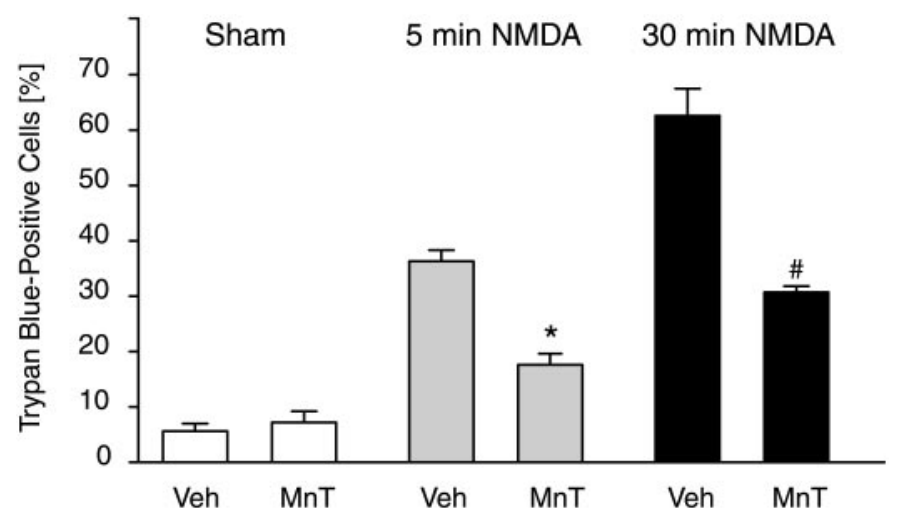

Figure 1. Neuroprotection by the SOD mimetic MnTBP. Cultured rat hippocampal neurons were exposed to $300 \mu \mathrm{M}$ NMDA in $\mathrm{Mg}^{2+}$-free HBS for either 5 or $30 \mathrm{~min}$, washed, and returned to the original culture medium. Sham-washed cultures were exposed for $30 \mathrm{~min}$ to $\mathrm{Mg}^{2+}$-free HBS devoid of NMDA. Cultures were pretreated for 60 min with $100 \mu \mathrm{M}$ MnTBP $(M n T)$ or vehicle $(V e h)$. Treatments were continued during and after the NMDA exposure. Cell death was quantified by trypan-blue uptake after 24 hr. Data are means \pm SEM from $n=8-16$ cultures in two to four experiments per treatment. Different from 5 min NMDA-exposed controls: ${ }^{*} p<0.05$; different from 30 min NMDA-exposed controls: ${ }^{\#} p<0.05$.

Nonspecific binding was blocked by incubation in Tris-buffered saline containing bovine serum albumin, non-fat dry milk, and $0.05 \%$ Tween-20 for $1 \mathrm{hr}$ at room temperature. The blots were then incubated overnight at $4^{\circ} \mathrm{C}$ in blocking buffer containing the primary antibody. Antibodies used were a mouse monoclonal anti-cytochrome oxidase subunit I antibody (1D6-E1-A8; Molecular Probes) diluted 1:500, a rabbit polyclonal antiBcl-x antibody (kindly provided by Prof. C. Thompson, University of Pennsylvania) diluted 1:2000, or a mouse monoclonal anti- $\alpha$-tubulin antibody (clone DM 1A; Sigma) diluted 1:1,000. Afterward, membranes were washed and incubated with anti-mouse or anti-rabbit IgG-horseradish peroxidase conjugate (1:5000; Promega, Mannheim, Germany). Antibodyconjugated peroxidase activity was visualized using the SuperSignal chemiluminescence reagent (Pierce, Rockford, IL).

Statistics. Data are given as means \pm SEM. For statistical comparison, $t$ test or one-way ANOVA followed by Tukey's test were used. For statistical comparison of Et and R-123 fluorescence data, Mann-Whitney $U$ test and Kruskal-Wallis H-test for non-parametric data were used. $P$ values smaller than 0.05 were considered to be statistically significant.

\section{RESULTS}

\section{Excitotoxic neuron death is sensitive to treatment with a cell-permeable SOD mimetic}

To induce a $\mathrm{Ca}^{2+}$-dependent excitotoxic cell death, we exposed cultured rat hippocampal neurons to the selective glutamate receptor agonist NMDA $(300 \mu \mathrm{M})$. A 5 min exposure to NMDA induced excitotoxic cell death in $36.3 \pm 2.0 \%$ of the hippocampal neurons determined by the uptake of the membrane-impermeable dye trypan blue $24 \mathrm{hr}$ after the exposure (Fig. 1). Prolonging the period of the NMDA exposure to $30 \mathrm{~min}$ increased excitotoxic neurodegeneration to $62.6 \pm 4.9 \%$. In agreement with previous reports demonstrating an important role of ROS in excitotoxic neuron death, NMDA-induced cell death after a brief or prolonged exposure was significantly reduced in cultures pretreated for 60 min with the cell-permeable SOD mimetic MnTBP $(100 \mu \mathrm{M})($ Fig. 1) or the lipophilic antioxidant $( \pm)$ - $\alpha$-tocopherol $(100 \mu \mathrm{M})$ (data not shown). Despite the common sensitivity to antioxidant treatment, there were differences in the mode of cell death after the 5 and $30 \mathrm{~min}$ NMDA exposure. Immediately after termination of the $30 \mathrm{~min}$ NMDA exposure, there was a statistically significant increase in the percentage of trypan blue-positive cells that further increased over time. In contrast, after the 5 min NMDA exposure the percentage of damaged neurons did not increase up to $2 \mathrm{hr}$, but tended to increase after $4 \mathrm{hr}$, and eventually reached the level of statistical significance after $8 \mathrm{hr}$ (Table 1).

\section{Recovery of mitochondrial superoxide production after toxic glutamate receptor overactivation}

Because ROS appeared to be required for the expression of excitotoxic neuron death, we next monitored the time course of super-
Table 1. Time course of neuronal degeneration after brief $(5 \mathrm{~min})$ or prolonged $(30 \mathrm{~min})$ exposure of cultured rat hippocampal neurons to NMDA

\begin{tabular}{lccc}
$\begin{array}{l}\text { Time after exposure } \\
\text { (hr) }\end{array}$ & $\begin{array}{l}\text { Trypan blue-positive cells } \\
(\%)\end{array}$ & $n$ & $p$ value \\
\hline Sham & $8.6 \pm 0.9$ & 24 & \\
NMDA (5 min) & & & \\
$\quad 0$ & $9.8 \pm 1.3$ & 12 & 1.000 \\
2 & $11.1 \pm 1.6$ & 12 & 0.967 \\
4 & $13.7 \pm 1.8$ & 12 & 0.209 \\
8 & $30.9 \pm 1.1^{*}$ & 15 & 0.000 \\
24 & $40.2 \pm 1.3^{*}$ & 20 & 0.000 \\
NMDA (30 min) & & & \\
0 & $27.0 \pm 2.3^{*}$ & 8 & 0.000 \\
2 & $33.0 \pm 2.0^{*}$ & 12 & 0.000 \\
4 & $35.8 \pm 3.1^{*}$ & 8 & 0.000 \\
8 & $41.7 \pm 3.1^{*}$ & 8 & 0.000 \\
24 & $60.5 \pm 2.0^{*}$ & 12 & 0.000
\end{tabular}

Cultured rat hippocampal neurons were exposed for 5 or 30 min to NMDA $(300 \mu \mathrm{M})$ or $\mathrm{Mg}^{2+}$-free HBS (Sham), washed, and returned to the original culture medium. After the indicated period of time, cell death was quantified by trypan-blue exclusion. Data are means \pm SEM from $n$ cultures in two to five separate experiments per time point. Values of sham-exposed controls did not differ statistically and were pooled for further statistical analysis. ${ }^{*}$ Different from sham-exposed controls (ANOVA and Tukey test; $p<0.05$ ).

oxide production during and after NMDA exposure. Superoxide production was determined with the oxidation-sensitive probe $\mathrm{HEt}$ in combination with digital video microscopy (Bindokas et al., 1996). Control experiments demonstrated a constant rate of $\mathrm{HEt}$ oxidation in cultures exposed to buffer (HBS) only (data not shown). When cells were continuously exposed to NMDA (300 $\mu \mathrm{M})$, HEt oxidation increased significantly with a maximal rate after $10 \mathrm{~min}$ of exposure (Fig. 2a). We and others have shown previously that NMDA-induced $\mathrm{Ca}^{2+}$ influx and the subsequent production of superoxide via the mitochondrial respiratory chain cause this increase, because both removal of extracellular $\mathrm{Ca}^{2+}$ or pretreatment with inhibitors of mitochondrial complex I reduced NMDA-induced superoxide production (Dugan et al., 1995; Sengpiel et al., 1998; Castilho et al., 1999). Interestingly, when cells were exposed to NMDA for only $5 \mathrm{~min}$ (which was sufficient to cause excitotoxic neuron death), superoxide production remained elevated for a further $10 \mathrm{~min}$ period after wash-out of NMDA but then rapidly returned to baseline levels (Fig. 2b).

\section{Delayed mitochondrial depolarization after toxic glutamate receptor overactivation}

Mitochondrial depolarization has been shown to be an early signal specific for excitotoxin exposure (White and Reynolds, 1996). Moreover, it has been reported that delayed excitotoxic neuron death is associated with a recovery of mitochondrial membrane potential after excitotoxin exposure (Ankarcrona et al., 1995). We were therefore interested to determine the uptake of R-123, a voltage-sensitive probe that is widely used to detect changes in mitochondrial membrane potential, during and after the $5 \mathrm{~min}$ NMDA exposure. In cultures exposed to NMDA for $5 \mathrm{~min}$, we observed a tendency toward a decrease in neuronal R-123 fluorescence ratios, which, however, did not reach the level of statistical significance (Student's $t$ test: $p=0.231$; Mann-Whitney $U$ test: $p=$ $0.712 ; n=110$ NMDA-exposed and $n=129$ sham-exposed neurons in three separate experiments per treatment), suggesting that mitochondrial depolarization was absent or below the level of detection (Fig. 3). Moreover R-123 fluorescence ratios $2 \mathrm{hr}$ after exposure to NMDA were indistinguishable from that of shamexposed controls. However, a significant decline in the R-123 fluorescence ratio was observed $6 \mathrm{hr}$ after the NMDA exposure, suggesting a delayed mitochondrial depolarization. 
a

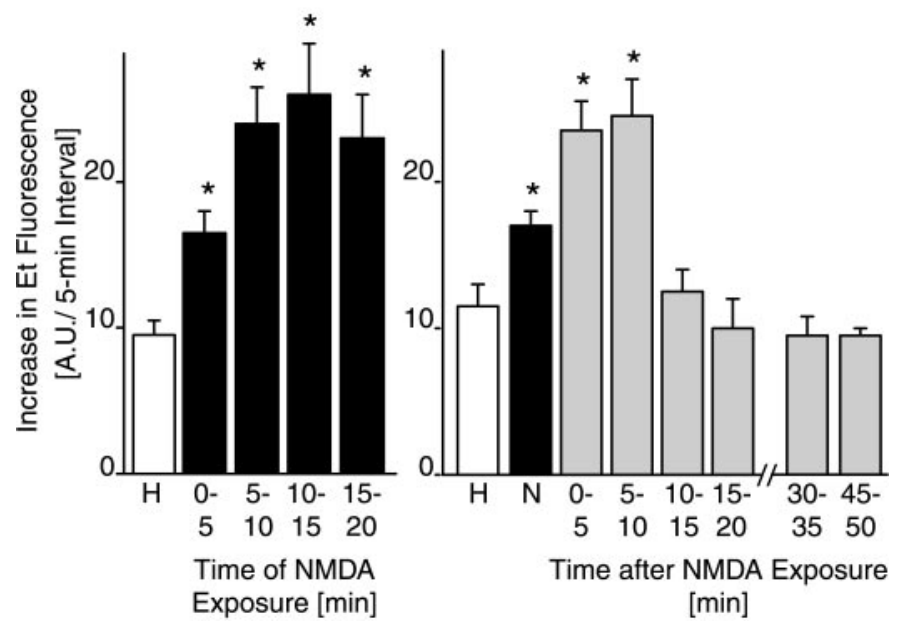

Figure 2. Superoxide production during and after exposure to NMDA. Cultures were incubated with HBS supplemented with $2 \mu \mathrm{g} / \mathrm{ml}$ HEt. The rate of HEt oxidation was determined in $5 \mathrm{~min}$ intervals using digital video microscopy. Extracellular solution was exchanged every $5 \mathrm{~min}$ by a fresh solution. $a$, Superoxide production increases during exposure to NMDA. Cultures were exposed for $5 \mathrm{~min}$ to $\mathrm{Mg}^{2+}$-free $\operatorname{HBS}(H)$ to record baseline superoxide production and were then exposed to NMDA $(300 \mu \mathrm{M}) . b$, Recovery of intracellular superoxide production after a brief glutamate receptor overactivation. Cultured rat hippocampal neurons were exposed to $\mathrm{Mg}^{2+}$-free $\mathrm{HBS}(H)$ for $5 \mathrm{~min}$ to record baseline superoxide production, and were then exposed to $300 \mu \mathrm{M}$ NMDA for $5 \mathrm{~min}(N)$. Afterward, extracellular solution was exchanged for HBS supplemented with $1 \mu \mathrm{M}$ of the NMDA antagonist dizocilpine. Data are means \pm SEM from $n=27$ and 65 neurons in four and nine experiments per treatment, respectively. Different from baseline superoxide production (HBS): ${ }^{*} p<0.05$. A.U., Arbitrary fluorescence unit.

\section{Glutamate receptor overactivation induces mitochondrial cytochrome $c$ release}

Delayed excitotoxicity associated with a recovery of mitochondrial energetics has been suggested to exhibit features of apopototic cell death (Ankarcrona et al., 1995). Mitochondrial cytochrome $c$ release is an important upstream trigger to activate apoptosis (Liu et al., 1996; Li et al., 1997) and in some systems is accompanied by mitochondrial depolarization (Kroemer et al., 1998; but see BossyWetzel et al., 1998; Krohn et al., 1998, 1999). Therefore, we investigated changes in cytochrome $c$ distribution after a $5 \mathrm{~min}$ NMDA exposure by immunofluorescence microscopy using a monoclonal antibody specific for native cytochrome c. In shamexposed controls, cytochrome $c$ immunoreactivity was distributed in the cytoplasm in a rod-like pattern that excluded the nucleus (Fig. 4). In cells exposed for 5 min to NMDA, a delayed loss of mitochondrial cytochrome $c$ immunofluorescence occurred. Cytochrome $c$ immunoreactivity was largely intact $2 \mathrm{hr}$ after the NMDA exposure and colocalized with the potential-insensitive mitochondrial marker, Mitotracker Green FM. By $8 \mathrm{hr}$, in contrast, the majority of the hippocampal neurons showed decreased, diff use cytochrome $c$ immunofluorescence. In these cells, mitochondria could still be labeled with Mitotracker Green FM or by doublestaining with an antibody against the mitochondrial matrix protein SOD-2. Quantification of cells that remained positive for mitochondrial markers and excluded trypan-blue revealed that cytochrome $c$ loss occurred in $54.2 \pm 2.7 \%$ of the hippocampal neurons, compared with $4.9 \pm 0.4 \%$ in sham-exposed controls and $7.9 \pm$ $0.2 \%$ in cultures $2 \mathrm{hr}$ after the NMDA exposure (data from three separate experiments per treatment).

\section{Loss of cytochrome $c$ is accompanied by a secondary increase in mitochondrial superoxide production}

A pronounced loss of cytochrome $c$ as seen after NMDA exposure could be associated with a disruption of the mitochondrial electron transport and accumulation of reducing equivalents in the respira- a
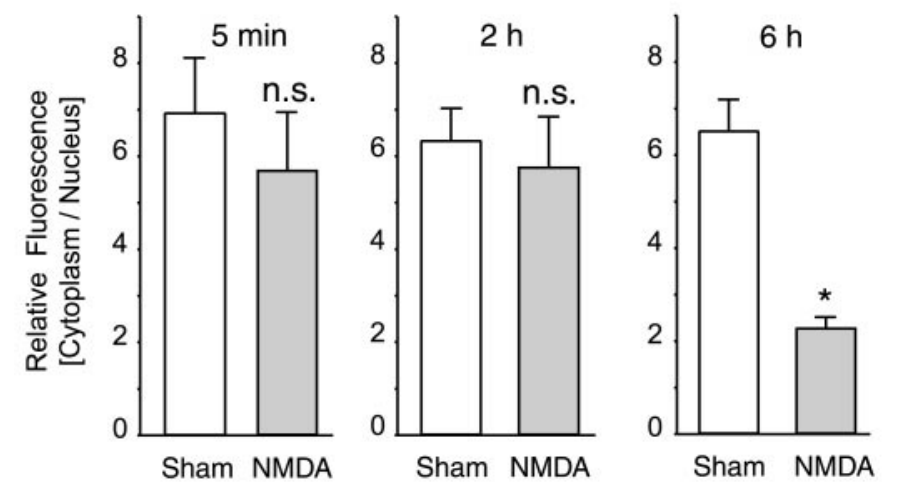

b
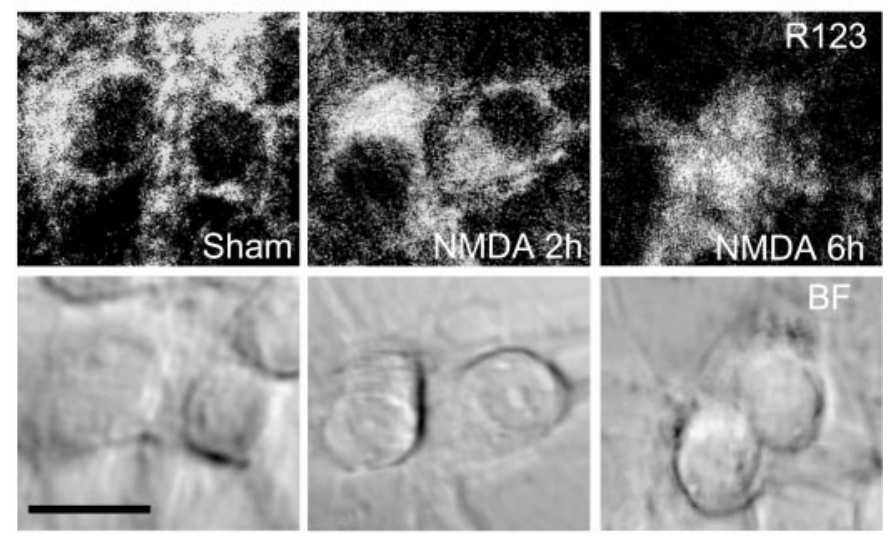

Figure 3. Mitochondrial potential changes during and after brief NMDA exposure. Live confocal microscopy imaging of R-123 uptake was performed in hippocampal neurons after a $5 \mathrm{~min}$ exposure to NMDA (300 $\mu \mathrm{M})$ or $\mathrm{Mg}^{2+}$-free HBS (Sham), as well as 2 or $6 \mathrm{hr}$ after the respective exposure. $a$, Histograms showing the average R-123 fluorescence ratio between the soma and the nucleus. Note that $6 \mathrm{hr}$ after exposure to NMDA, neurons had a significantly lower ratio then in all other experimental configurations. Data are means \pm SEM from $n=25-136$ neurons and $n=3$ separate experiments per treatment. Difference between respective NMDA- and sham-exposed cells: ${ }^{*} p<0.05$. n.s., Not statistically significant. b, Top row, Confocal R-123 fluorescence images; bottom row, bright-field $(B F)$ images. Images demonstrate different hippocampal neurons after sham exposure, $2 \mathrm{hr}$ after, or $6 \mathrm{hr}$ after a 5 min NMDA exposure. The sham and the $2 \mathrm{hr}$ NMDA experiment show neurons with a clear fluorescence signal in the soma and almost none in the nucleus region; however, the $6 \mathrm{hr}$ NMDA experiment shows a decrease in the cytoplasmic R-123 fluorescence, as well as an increased fluorescence in the nuclei, leading to an almost equally distributed R-123 dye. Scale bar, $10 \mu \mathrm{m}$.

tory chain. One potential consequence thereof is an increased formation of superoxide attributable to a shift from the normal four-electron reduction of molecular oxygen to an one-electron reduction (Boveris et al., 1976; Turrens and Boveris, 1980). We were therefore interested in quantifying superoxide production in the hippocampal neuron cultures after the mitochondrial release of cytochrome $c$. Under conditions of mitochondrial depolarization (Fig. 3), mitochondrially generated Et may be released into the cytoplasm, resulting in an artificial fluorescence enhancement (Castilho et al., 1999). We therefore quantified the amount of HEt oxidized to Et over a period of $30 \mathrm{~min}$ in cell lysates prepared at various time points after a 5 min NMDA exposure. In support of the above hypothesis, we observed a secondary burst in superoxide production that reached the level of statistical significance after 4 hr (Fig. 5a). The lysate method also detected the immediate increase in HEt oxidation occurring during and shortly after a $5 \mathrm{~min}$ NMDA exposure $[25.4 \pm 1.8$ arbitrary fluorescence unit $(\mathrm{AU}) / \mu \mathrm{g}$ protein in cultures exposed for $5 \mathrm{~min}$ to NMDA and allowed to recover for $25 \mathrm{~min}$ vs $14.0 \pm 2.8 \mathrm{AU} / \mu \mathrm{g}$ protein in sham-exposed 

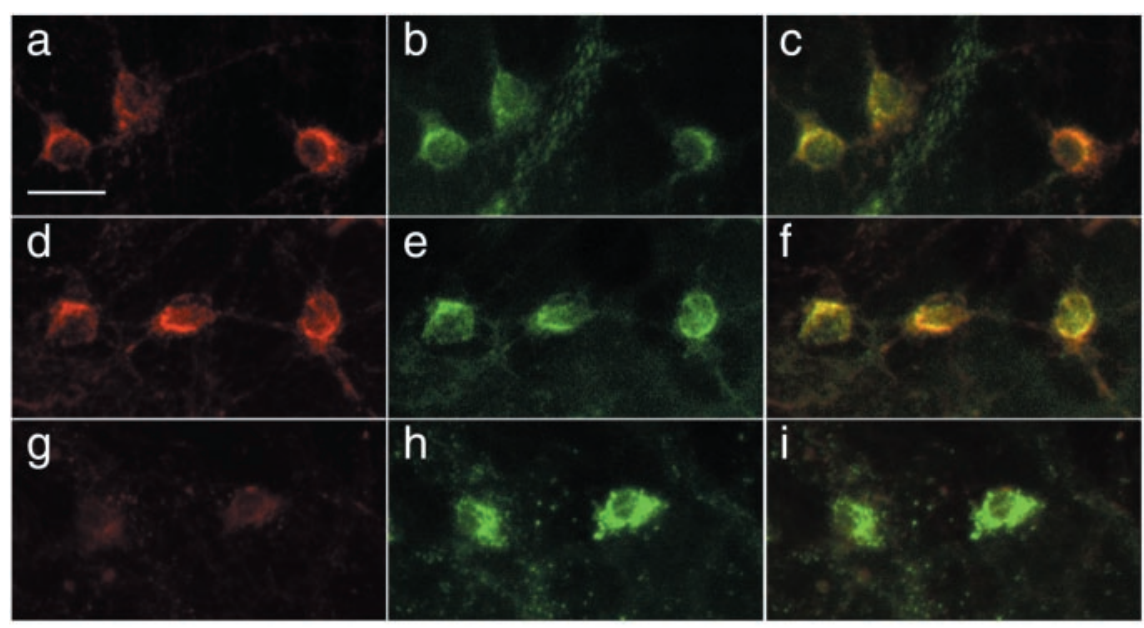

Cytochrome c

Mitotracker Green
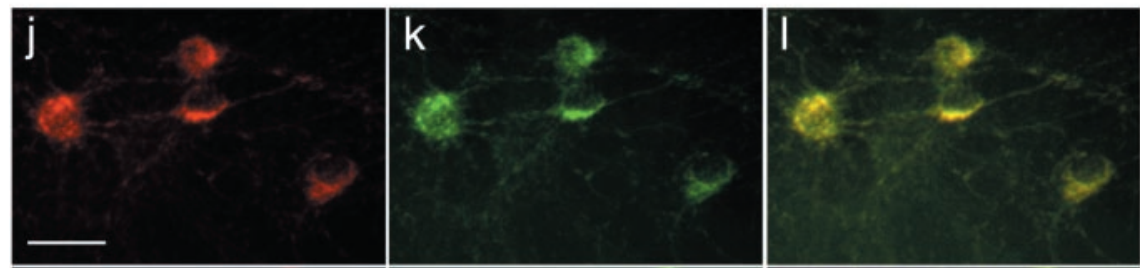

Overlay
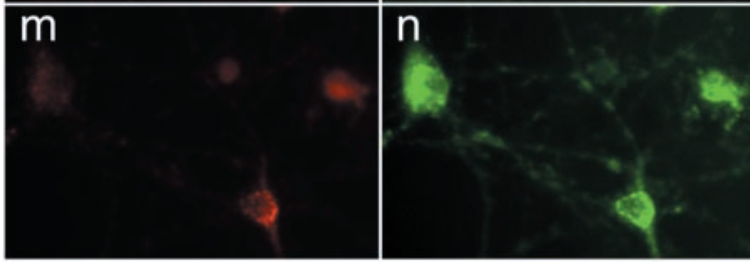

Cytochrome c
Overlay

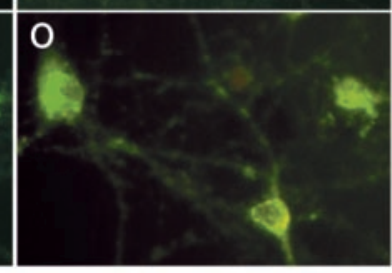

\section{Sham}

NMDA

$2 \mathrm{~h}$

NMDA

$8 \mathrm{~h}$

Sham

NMDA

a

b

Figure 4. Loss of mitochondrial cytochrome $c$ after glutamate receptor overactivation. $a-c$, Control culture $8 \mathrm{hr}$ after sham exposure showing a punctate or rod-like cytochrome $c$ immunofluorescence pattern that overlaps with Mitotracker Green FM fluorescence. $d-f$, Hippocampal neurons $2 \mathrm{hr}$ after NMDA exposure $(300 \mu \mathrm{M}, 5 \mathrm{~min})$. Note that cytochrome $c$ immunofluorescence was largely intact and colocalized with Mitotracker Green. $g-i$, Eight hours after the NMDA exposure, hippocampal neurons lost their cytochrome $c$ immunofluorescence, whereas Mitotracker Green FM fluorescence was largely preserved. $j-l$, Control culture $8 \mathrm{hr}$ after sham exposure showing overlap of cytochrome $c$ and SOD-2 immunofluorescence. $m-O$, Culture exposed to $300 \mu \mathrm{M}$ NMDA for $5 \mathrm{~min}$ and fixed after $8 \mathrm{hr}$. Note a decreased and diffuse cytochrome $c$ staining pattern, whereas SOD-2 immunofluorescence remained intense and punctate. Scale bar, $25 \mu \mathrm{m}$.

cultures; $n=4$ cultures per treatment; $p=0.015]$. After the $30 \mathrm{~min}$ NMDA exposure, superoxide production remained elevated at a constant level for up to $8 \mathrm{hr}$ (Fig. $5 b$ ).

To verify our finding of the delayed increase in superoxide production with a different assay, we used a DAB/Mn cytochemical method to detect intracellular superoxide formation (Fig. 6). Cultures were exposed to $\mathrm{Mg}^{2+}$-free HBS (sham) or NMDA for $5 \mathrm{~min}$ and analyzed after $6 \mathrm{hr}$. A 5 min exposure to NMDA increased the percentage of positively stained neurons significantly. A treatment with the complex I inhibitor rotenone $(2 \mu \mathrm{M})$ in combination with oligomycin $(2 \mu \mathrm{M})$ to inhibit reversal of the mitochondrial ATP synthase (Budd and Nicholls, 1996a,b; Sengpiel et al., 1998) significantly decreased the delayed superoxide production, suggesting that the origin of the superoxide was mainly mitochondrial (Fig. 6).

\section{Disruption of electron flow at the level of complex III increases superoxide production}

We then addressed the question of whether loss of cytochrome $c$ could be functionally related to the secondary increase in superoxide production. Cytochrome $c$ shuttles electrons between complexes III and IV of the mitochondrial respiratory chain. Treatment with the mitochondrial complex III inhibitor antimycin A (10 $\mu \mathrm{M})$ also increased superoxide production in the hippocampal neurons shown by the DAB/Mn cytochemical assay (Fig. 6). An increased superoxide production after an exposure to antimycin A was also detected by quantifying $\mathrm{HEt}$ oxidation in individual hippocampal neurons (Fig. 7a).

If electron flow was already inhibited at the level of complex III by a treatment with antimycin A, the NMDA-induced loss of cytochrome $c$ should fail to stimulate a further increase in superoxide production. In fact, quantification of HEt oxidation demonstrated that NMDA failed to stimulate a secondary increase in
5 min NMDA
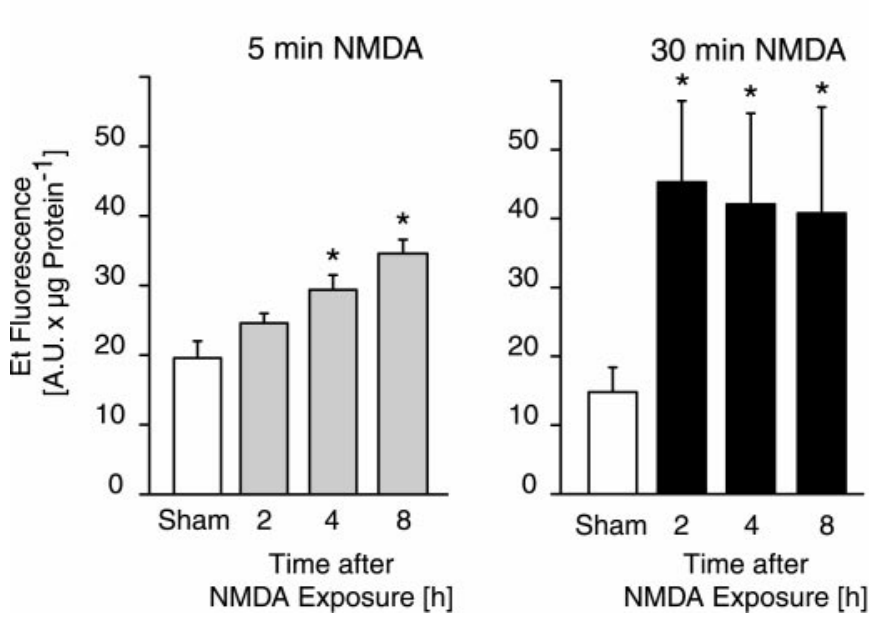

Figure 5. Delayed superoxide production in excitotoxic neuron death. Cultured rat hippocampal neurons were exposed to $300 \mu \mathrm{M}$ NMDA for either 5 $\min (a)$ or $30 \mathrm{~min}(b)$. Sham-washed cultures were exposed to $\mathrm{Mg}^{2+}$-free HBS. At the indicated time points after the exposure, cultures were treated with $\mathrm{HEt}(10 \mu \mathrm{g} / \mathrm{ml})$ for $30 \mathrm{~min}$ at $37^{\circ} \mathrm{C}$. Afterward, cells were homogenized with lysis buffer, and Et fluorescence of cellular extracts was quantified using a fluorescence microplate reader. Et fluorescence data are normalized for protein content. Data are means \pm SEM from $n=6-8$ cultures. Different from sham-exposed controls: ${ }^{*} p<0.05$. The experiment was performed in triplicate $(a)$ or duplicate $(b)$ and yielded comparable results. 

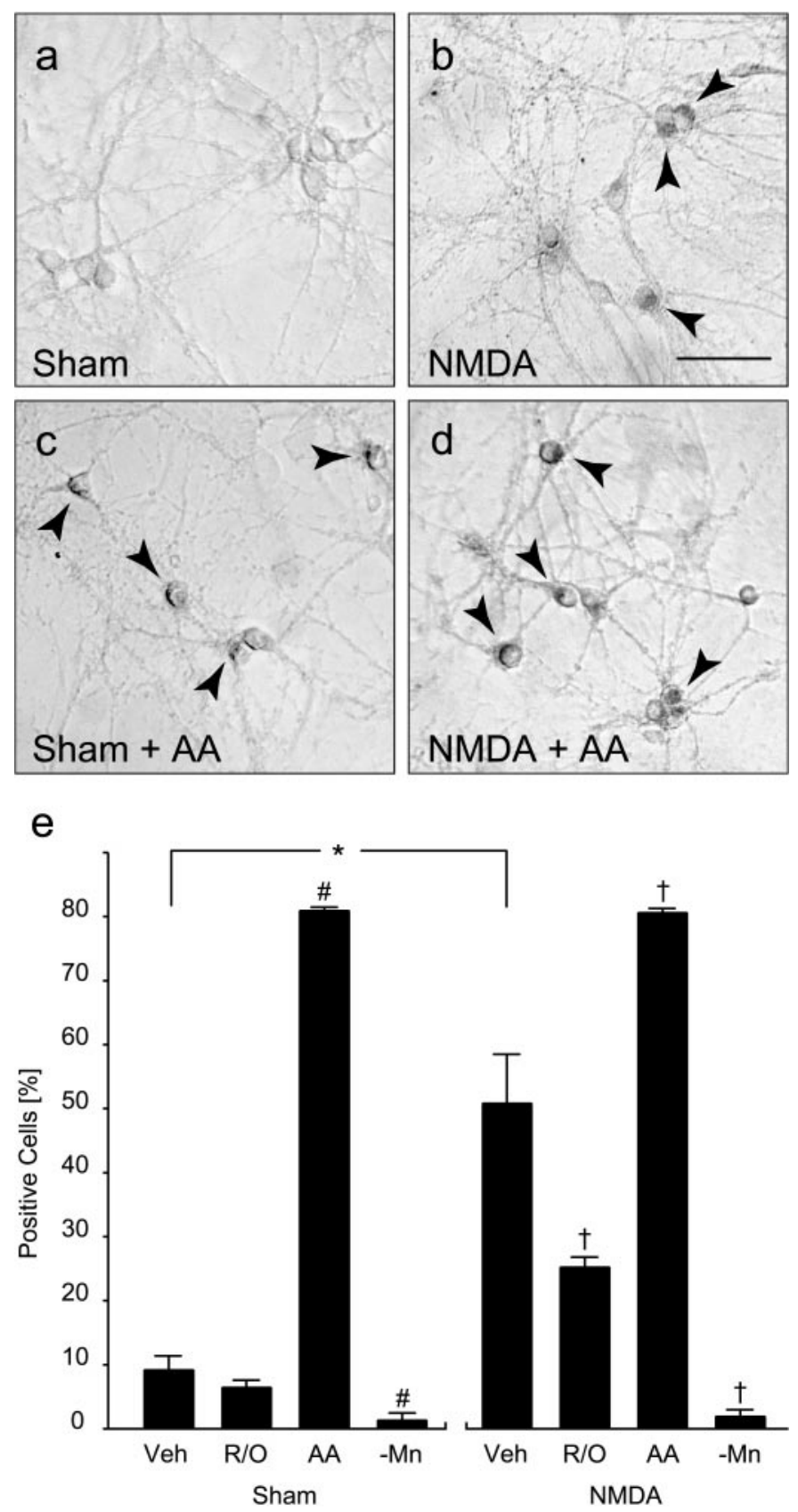

Figure 6. Cytochemical detection of superoxide production in cultured rat hippocampal neurons after glutamate receptor overactivation. Cultured rat hippocampal neurons were exposed for $5 \mathrm{~min}$ to NMDA $(300 \mu \mathrm{M})$ or $\mathrm{Mg}^{2+}$-free HBS (Sham), washed, and returned to the original culture medium. After $6 \mathrm{hr}$, the culture medium was replaced by HBS supplemented with $2.5 \mathrm{mM}$ DAB, $0.5 \mathrm{mM} \mathrm{MnCl}_{2}, 1 \mathrm{mM} \mathrm{NaN}_{3}, 1 \mu \mathrm{M}$ of the NMDA antagonist dizocilpine and mitochondrial respiratory chain inhibitors rotenone $(2 \mu \mathrm{M})$ plus oligomycin $(2 \mu \mathrm{M})(R / O)$, antimycin $\mathrm{A}(10 \mu \mathrm{M})(A A)$, or vehicle $(V e h)$. As a negative control, the reaction was performed in the absence of $\mathrm{MnCl}_{2}(-M n)$. Cultures were incubated for $60 \mathrm{~min}$ at $37^{\circ} \mathrm{C}$, fixed, and analyzed for positive staining. $a-d$, Bright-field images of hippocampal neuron cultures $6 \mathrm{hr}$ after sham exposure or NMDA exposure and treatment with or without antimycin A. Arrows indicate neurons with cytoplasmic precipitates. Scale bar, $50 \mu \mathrm{m}$. $e$, Quantification of Mn/DAB staining. Data are means \pm SEM from six cultures in two separate experiments. ${ }^{*} p<0.05$ : difference between sham- and NMDA-exposed cultures; ${ }^{\#} p<0.05$ : different from sham-exposed cultures. ${ }^{\dagger} p<0.05$ : different from NMDA-exposed cultures (ANOVA and Tukey's test; $p<0.05$ ).

superoxide production in cultures treated with antimycin A (Fig. $7 a)$. In contrast, NMDA was able to stimulate a secondary increase in superoxide production in cultures treated with paraquat (100 $\mu \mathrm{M})$, a redox cycling agent that increases superoxide independently a

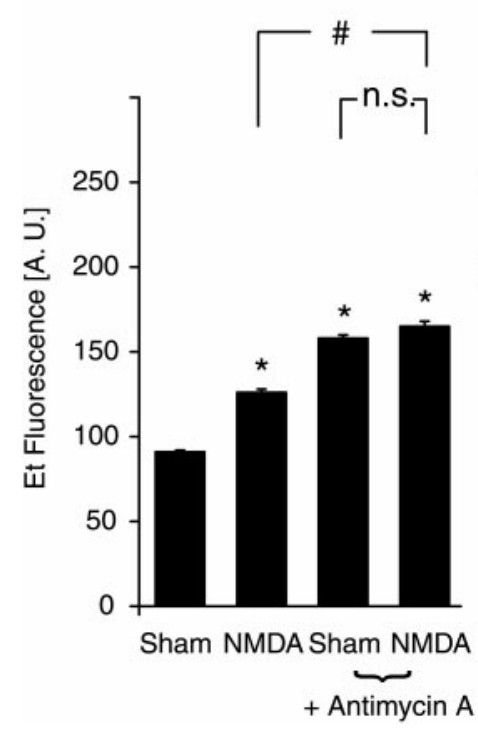

b

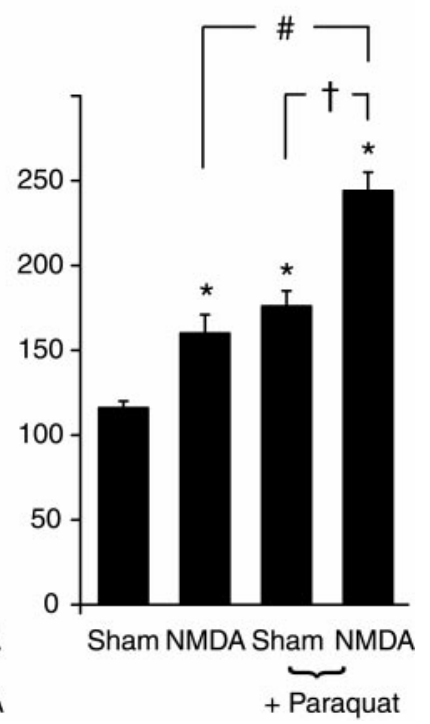

Figure 7. Antimycin A- and paraquat-induced superoxide production after exposure to NMDA. Cultured rat hippocampal neurons were exposed to $300 \mu \mathrm{M}$ NMDA or $\mathrm{Mg}^{2+}$-free HBS (Sham) for $5 \mathrm{~min}$, washed, and returned to the original culture medium. After $8 \mathrm{hr}$, cultures were incubated at $37^{\circ} \mathrm{C}$ in HBS supplemented with $2 \mu \mathrm{g} / \mathrm{ml} \mathrm{HEt}$ plus $1 \mu \mathrm{M}$ dizocilpine, and $10 \mu \mathrm{M}$ antimycin A $(a), 100 \mu \mathrm{M}$ paraquat $(b)$, or vehicle. Et production of individual hippocampal neurons was quantified by fluorescence microscopy. Data are means \pm SEM from $n=174-373$ neurons in two separate experiments per treatment. ${ }^{*} p<0.05$ : Different from sham-exposed controls; ${ }^{\#} p<0.05$ : different from NMDA-exposed controls; ${ }^{\dagger} p<0.05$ : different from respective drug-treated control. n.s., Not statistically significant. A.U., Arbitrary fluorescence units.

of the activity of the mitochondrial respiratory chain (Smith et al., 1978) (Fig. 7b).

\section{Cytochrome $c$ release upstream of mitochondrial superoxide production}

To establish whether superoxide production occurs upstream or downstream of mitochondrial cytochrome $c$ release, we performed experiments in D283 cells lacking a functional respiratory chain ( $\rho^{-}$cells). As shown in Figure $8 a, \rho^{-}$cells lacked expression of the mtDNA-encoded cytochrome oxidase subunit I. In contrast, expression of nuclear encoded proteins, including the anti-apoptotic protein $\mathrm{Bcl}-\mathrm{xl}$ and the cytoskeletal protein $\alpha$-tubulin, remained unchanged. Because D283 cells have no functional glutamate receptors, cytochrome $c$ release was induced by an exposure to the apoptosis-inducing agent staurosporine. D283 $\rho^{-}$cells showed resistance to the toxic effect of the complex I inhibitor rotenone but were killed by staurosporine as readily as D283 control cells (Figs. $8 b, c)$. Confocal laser scanning microscopy revealed that both control and $\rho^{-}$cells released cytochrome $c$ from mitochondria after treatment with $3 \mu \mathrm{M}$ staurosporine, resulting in a diffuse cytochrome $c$ immunofluorescence and a redistribution of the immunofluorescence into the nucleus (Fig. $8 d$ ). Because release of cytochrome $c$ triggers the activation of caspases, we determined caspase-3-like protease activity in cell lysates of control and $\rho^{-}$ cells after the exposure to staurosporine. This treatment caused a significant increase in cleavage of the fluorigenic substrate AcDEVD-AMC in both cell types (Fig. 8e). However, an increased production of superoxide was observed only in control cells (Fig. 8f).

\section{Delayed administration of a SOD mimetic rescues neurons from excitotoxic neuron death}

Finally, we investigated the importance of the delayed superoxide production for excitotoxic neuron death by determining the effect of a post-treatment with the SOD mimetic MnTBP. Treatment with MnTBP 2 hr after termination of the 5 min NMDA exposure (after the first increase in superoxide production, but before the 
a

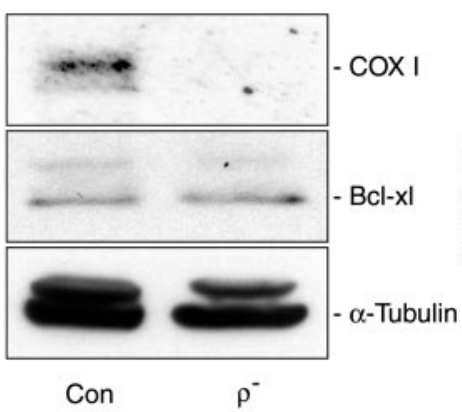

d

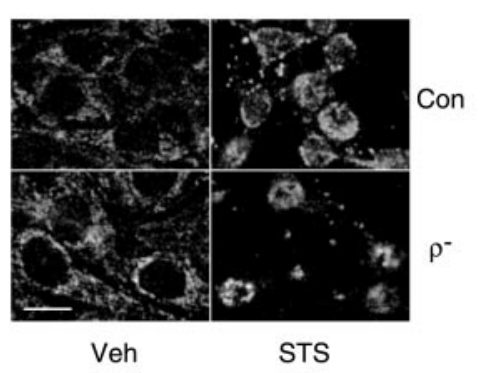

b

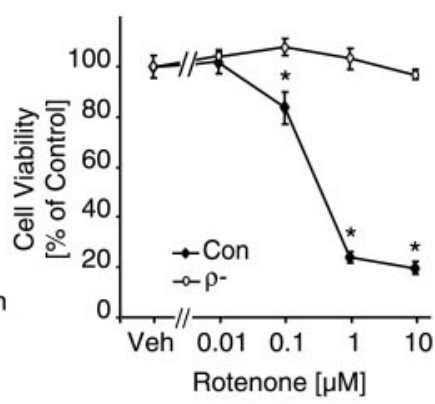

C

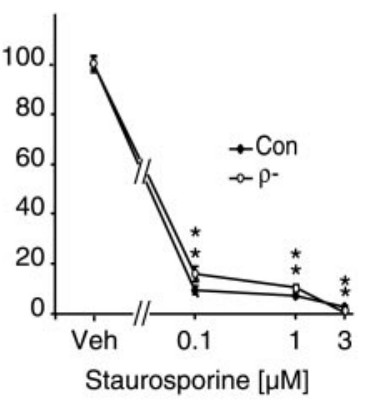

e

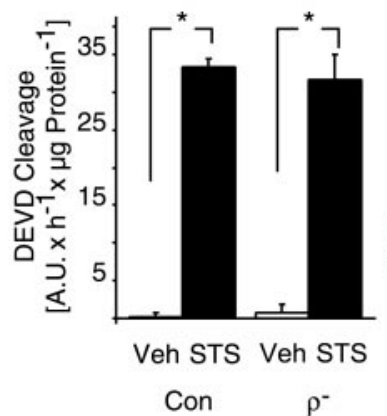

\section{f}

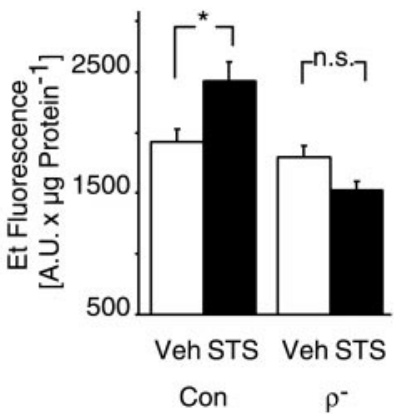

Figure 8. Cytochrome $c$ release, caspase activation, and superoxide production in medulloblastoma D283 control and $\rho^{-}$cells. $a$, Western blot analysis showing reduced expression of cytochrome oxidase subunit I in $\rho^{-}$cells, whereas expression of Bcl-xl and $\alpha$-tubulin remains unchanged. $b$, Rotenone is toxic to control cells, whereas $\rho^{-}$cells are resistant. Cells were incubated with rotenone, and cell viability was determined after 24 hr. Data are means \pm SEM from $n=8$ cultures per treatment. $c$, D283 control and $\rho^{-}$cells are equally sensitive to the apoptosis-inducing agent staurosporine. Cultures were exposed to staurosporine for $24 \mathrm{hr}$. Data are means \pm SEM from $n=8$ cultures per treatment. $d$. Cytochrome $c$ release in D283 control and $\rho^{-}$cells detected $6 \mathrm{hr}($ Con $)$ and $8 \mathrm{hr}\left(\rho^{-}\right)$after exposure to $3 \mu \mathrm{M}$ staurosporine by immunofluorescence analysis and confocal laser scanning microscopy. Note the diffuse staining pattern in either cell type. Scale bar, $25 \mu \mathrm{m}$. $e$, Caspase-3-like protease activity increases in both D283 control and $\rho^{-}$cells. Cytosolic extracts were prepared $6 \mathrm{hr}(\mathrm{Con})$ and $8 \mathrm{hr}\left(\rho^{-}\right)$after the exposure to staurosporine. Cleavage of fluorigenic Ac-DEVD-AMC was monitored over $1 \mathrm{hr}$ using a fluorescent plate reader. Data are means \pm SEM from $n=8$ cultures per treatment. $f$, Superoxide production in D283 control and $\rho^{-}$cells. Cultures were exposed to $3 \mu \mathrm{M}$ staurosporine for $6 \mathrm{hr}(\mathrm{Con})$ and $8 \mathrm{hr}\left(\rho^{-}\right)$and treated with HEt $(10 \mu \mathrm{g} / \mathrm{ml})$ for the last 30 min of the exposure. Afterward, cells were homogenized with lysis buffer, and Et fluorescence of cellular extracts was quantified using a fluorescence microplate reader. Data are means \pm SEM from $n=15$ and 16 cultures, respectively. Different from respective vehicle-treated cultures: ${ }^{*} p<0.05$.

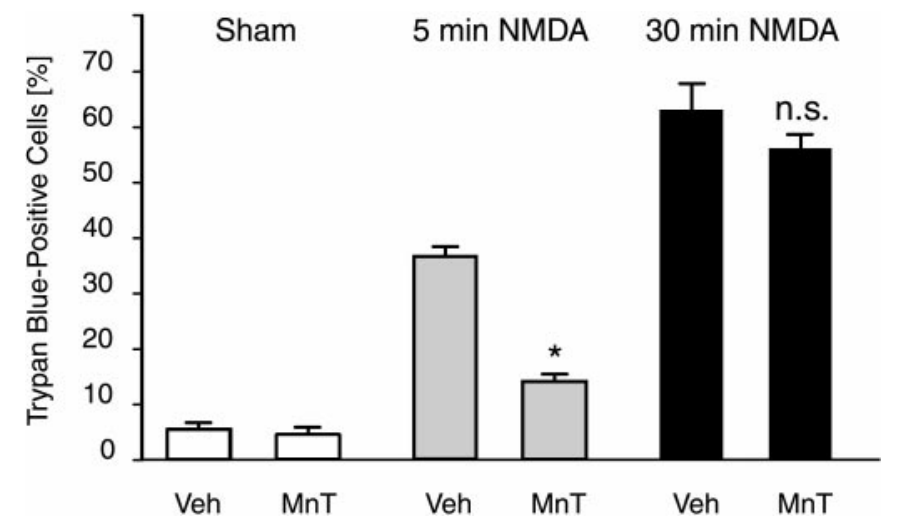

Figure 9. Post-treatment with the SOD mimetic MnTBP rescues hippocampal neurons from excitotoxic cell death. Cultured rat hippocampal neurons were exposed for 5 or $30 \mathrm{~min}$ to NMDA $(300 \mu \mathrm{M})$ or $\mathrm{Mg}^{2+}$-free HBS (Sham), washed, and returned to the original culture medium. Two hours after the exposure, cultures received $100 \mu \mathrm{M}$ MnTBP $(M n T)$ or vehicle $(V e h)$. After $22 \mathrm{hr}$, cell death was quantified by trypan-blue exclusion. Data are means \pm SEM from $n=8-12$ cultures in two to three separate experiments per treatment. Different from respective $5 \mathrm{~min}$ NMDA-exposed controls: ${ }^{*} p<0.05$. n.s., Not statistically significant.

secondary increase) conferred a similar degree of protection as achieved with the 1 hr pretreatment (Fig. 9; compare with Fig. 1). In contrast, MnTBP exerted no effect when administered $2 \mathrm{hr}$ after a 30 min NMDA exposure (Fig. 9).

Interestingly, post-treatment of the hippocampal neuron cultures with the mitochondrial $\mathrm{Ca}^{2+}$ uptake inhibitor ruthenium red (25 $\mu \mathrm{M}) 2 \mathrm{hr}$ after termination of the 5 min NMDA exposure was also able to reduce excitotoxic neuron death $(19.9 \pm 3.1 \%$ cell death in ruthenium red-treated, NMDA-exposed cultures vs $35.3 \pm 2.4 \%$ cell death in NMDA-exposed cultures; $p<0.05 ; n=4$ cultures per treatment), supporting the concept of delayed mitochondrial dysfunction.

\section{DISCUSSION}

In the present study, we demonstrate that a brief exposure of cultured rat hippocampal neurons to the glutamate receptor agonist NMDA induced a delayed excitotoxic neuron death associated with a biphasic increase in superoxide production. The initial increase occurs during and shortly after the NMDA exposure. Cellular $\mathrm{Ca}^{2+}$ overloading and subsequent production of superoxide via the mitochondrial respiratory chain have been shown to cause this immediate increase (Dugan et al., 1995; Reynolds and Hastings, 1995; Bindokas et al., 1996; Sengpiel et al., 1998). The initial superoxide production rapidly returns to baseline levels after wash-out of NMDA, and mitochondria remain polarized (Figs. 2, $3)$. However, recovery of mitochondria is transient and subsequently followed by a delayed mitochondrial depolarization, release of cytochrome $c$, and a secondary rise in superoxide production (Figs. 3-5).

Mitochondrial $\mathrm{Ca}^{2+}$ overloading could be the key process to trigger both the immediate, potentially reversible, and the delayed mitochondrial dysfunction. Inhibition of mitochondrial $\mathrm{Ca}^{2+}$ uptake by mitochondrial depolarization during or shortly after glutamate receptor overactivation is able to prevent mitochondrial $\mathrm{Ca}^{2+}$ overloading and excitotoxic neuron death (Budd and Nicholls, 1996b; Castilho et al., 1998; Sengpiel et al., 1998; Stout et al., 
1998). Peng and coworkers (1998) have recently demonstrated a prolonged mitochondrial $\mathrm{Ca}^{2+}$ overloading persisting after NMDA receptor overactivation in cultured striatal neurons. It is conceivable that this prolonged mitochondrial $\mathrm{Ca}^{2+}$ overloading induces a disturbance of mitochondrial functions that worsens over time, leading to mitochondrial depolarization and cytochrome $c$ release. Alternatively, it is possible that mitochondria receive a second challenge once the excitotoxic cascade is activated. Lipid peroxidation, activation of proteases and lipases, or mitochondrialindependent generation of ROS may trigger a delayed dysfunction (Siman et al., 1989; Dawson et al., 1991; Choi, 1994). The role of delayed mitochondrial $\mathrm{Ca}^{2+}$ accumulation was supported in the present study by the protective effect of the mitochondrial $\mathrm{Ca}^{2+}$ uptake inhibitor ruthenium red administered $2 \mathrm{hr}$ after the NMDA exposure. This protective effect appears to be equally or even more potent than those of NMDA antagonists or voltage-sensitive $\mathrm{Ca}^{2+}$ channel blockers when administered after excitotoxin exposure (Hartley and Choi, 1989; Prehn et al., 1995).

NMDA-induced mitochondrial $\mathrm{Ca}^{2+}$ uptake may result in increased permeability of the outer mitochondrial membrane and subsequent loss of the pro-apoptotic factor cytochrome $c$ (Fig. 4). $\mathrm{Ca}^{2+}$-induced cytochrome $c$ release may involve the opening of the mitochondrial permeability transition pore or pore-independent pathways (Andreyev and Fiskum, 1999; He et al., 2000). Although many studies have focused on the role of cytochrome $c$ release to activate the caspase cascade (Liu et al., 1996; Li et al., 1997), loss of cytochrome $c$ may also affect mitochondrial respiration and free radical production. Cytochrome $c$ transports electrons between mitochondrial complexes III and IV. A disruption of the mitochondrial electron flow caused by a significant loss of cytochrome $c$ will maintain complex I and the ubiquinone at complex II in the reduced state. This condition has previously been shown to favor one-electron reduction of molecular oxygen, presumably because of an autooxidation of complex I and ubiquinone (Boveris et al., 1976; Turrens and Boveris, 1980). This is a potential mechanism for the well known effect of complex III and IV inhibitors to increase the mitochondrial production of superoxide (Figs. 6, 7). In fact, inhibition of mitochondrial electron transfer at the level of complex I (under conditions that inhibit reversal of the mitochondrial ATP synthase) significantly reduced the secondary increase in superoxide production after NMDA exposure (Fig. 6).

Interestingly, cytochrome $c$ release and superoxide production also occur at similar time points in the death cascade during trophic factor withdrawal- or staurosporine-induced neuronal apoptosis (Greenlund et al., 1995; Deshmukh and Johnson, 1998; Krohn et al., 1998, 1999; Martinou et al., 1999). Inhibition of mitochondrial electron flow and increased mitochondrial superoxide production secondary to cytochrome $c$ release have been observed during Fasand staurosporine-mediated apoptosis of Jurkat and HL60 cells (Krippner et al., 1996; Cai and Jones, 1998). In support of these data, NMDA failed to stimulate a secondary increase in superoxide production when electron flow through complex III was already inhibited by antimycin A (Fig. 7). Moreover, in a neural cell line deficient in mitochondrial respiration (medulloblastoma D283 $\rho^{-}$ cells), cytochrome $c$ release and activation of apoptosis were preserved, whereas an increased superoxide production could not be detected (Fig. 8) (also see Jiang et al., 1999). Therefore, cytochrome $c$ release occurs upstream of mitochondria-derived ROS production.

It should also be noted that previous studies have found little evidence for a prominent activation of executioner caspases after glutamate receptor overactivation (Armstrong et al., 1997; Yu et al., 1999; Lankiewicz et al., 2000). The discrepancy between mitochondrial cytochrome $c$ release and the lack of activation of executioner caspases in our model of excitotoxic neuron death has been shown to be attributable to $\mathrm{Ca}^{2+}$ - and calpain-dependent suppression of the caspase cascade (Lankiewicz et al., 2000). On the other hand, the protective effect of post-treatment with the SOD mimetic MnTBP demonstrated that the secondary production of superoxide played an important role in the execution of excito- toxic neuron death (Fig. 9). Assuming that the delayed production of superoxide is caused by mitochondrial cytochrome $c$ release (see Discussion above), loss of cytochrome $c$ may induce cell death independent of caspases. Likewise, in several models of neuronal apoptosis, inhibition of executioner caspases is able to reduce the biochemical and morphological signs of apoptosis but does not necessarily inhibit cell death (Stefanis et al., 1996; Taylor et al., 1997; Krohn et al., 1998). On the other hand, inhibition of superoxide production has been shown to protect against neuronal apoptosis (Greenlund et al., 1995; Jordan et al., 1995; Schulz et al., 1996; Krohn et al., 1998). Therefore, delayed mitochondrial superoxide production may significantly contribute to neuron death in excitotoxicity and apoptosis.

\section{REFERENCES}

Andreyev AY, Fiskum G (1999) Calcium induced release of mitochondrial cytochrome c by different mechanisms selective for brain versus liver. Cell Death Differ 6:825-832.

Andreyev AY, Fahy B, Fiskum G (1998) Cytochrome c release from brain mitochondria is independent of the mitochondrial permeability transition. FEBS Lett 20:373-376.

Ankarcrona M, Dypbukt JM, Bonfoco E, Zhivotovsky B, Orrenius S, Lipton SA, Nicotera P (1995) Glutamate-induced neuronal death: a succession of necrosis and apoptosis depending on mitochondrial function. Neuron 15:961-973.

Armstrong RC, Aja TJ, Hoang KD, Gaur S, Bai X, Alnemri ES, Litwack G, Karanewsky DS, Fritz LC, Tomaselli KJ (1997) Activation of the CED3/ICE-related protease CPP32 in cerebellar granule neurons undergoing apoptosis but not necrosis. J Neurosci 15:553-562.

Bindokas VP, Jordan J, Lee CC, Miller RJ (1996) Superoxide production in rat hippocampal neurons: sensitive imaging with ethidine. J Neurosci 16:1324-1336.

Bossy-Wetzel E, Newmeyer DD, Green DR (1998) Mitochondrial cytochrome $c$ release in apoptosis upstream of DEVD-specific caspase activation and independently of mitochondrial transmembrane depolarization. ЕMBO J 17:37-49.

Boveris A, Cadenas E, Stoppani AOM (1976) Role of ubiquinone in the mitochondrial generation of hydrogen peroxide. Biochem J 156:435-444.

Briggs RT, Robinson JM, Karnovsky ML, Karnovsky MJ (1986) Superoxide production by polymorphonuclear leukocytes. A cytochemical approach. Histochemistry 84:371-378.

Budd SL, Nicholls DG (1996a) A re-evaluation of the role of mitochondria in neuronal $\mathrm{Ca}^{2+}$ homeostasis. J Neurochem 66:403-411.

Budd SL, Nicholls DG (1996b) Mitochondria, calcium regulation, and acute glutamate excitotoxicity in cultured cerebellar granule cells. J Neurochem 67:2282-2291.

Cai JY, Jones DP (1998) Superoxide in apoptosis-mitochondrial generation triggered by cytochrome c loss. J Biol Chem 273:11401-11404.

Castilho RF, Hansson O, Ward MW, Budd SL, Nicholls DG (1998) Mitochondrial control of acute glutamate excitotoxicity in cultured cerebellar granule cells. J Neurosci 18:10277-10286.

Castilho RF, Ward MW, Nicholls DG (1999) Oxidative stress, mitochondrial function, and acute glutamate excitotoxicity in cultured cerebellar granule cells. J Neurochem 72:1394-1401.

Chan PH, Chu L, Chen SF, Carlson EJ, Epstein C (1990) Attenuation of glutamate-induced neuronal swelling and toxicity in transgenic mice overexpressing human CuZn-superoxide dismutase. Acta Neurochir (Wien) 51:245-247.

Choi DW (1987) Ionic dependence of glutamate neurotoxicity. J Neurosci 7:369-379

Choi DW (1994) Calcium and excitotoxic neuronal injury. Ann NY Acad Sci 747:162-171.

Dawson VL, Dawson TM, London ED, Bredt DS, Snyder SH (1991) Nitric oxide mediates glutamate neurotoxicity in primary cortical cultures. Proc Natl Acad Sci USA 88:6368-6371.

Deshmukh M, Johnson Jr EM (1998) Evidence of a novel event during neuronal death: development of competence-to-die in response to cytoplasmic cytochrome c. Neuron 21:695-705.

Dugan LL, Sensi SL, Canzoniero LMT, Handran SD, Rothman SM, Lin T-S, Goldberg MP, Choi DW (1995) Mitochondrial production of reactive oxygen species in cortical neurons following exposure to $N$-methylD-aspartate. J Neurosci 15:6377-6388.

Dykens JA (1994) Isolated cerebral and cerebellar mitochondria produce free radicals when exposed to elevated $\mathrm{Ca}^{2+}$ and $\mathrm{Na}^{+}$: implications for neurodegeneration. J Neurochem 63:584-591.

Ehrenberg B, Montana V, Wie MD, Wuskell JP, Loew LM (1988) Membrane potential can be determined in individual cells from the nernstian distribution of cationic dyes. Biophys J 53:785-794

Emaus RK, Grunwald R, Lemasters JJ (1986) Rhodamine 123 as a probe of transmembrane potential in isolated rat liver mitochondria: spectral and metabolic properties. Biochem Biophys Acta 850:436-448.

Falcieri E, Martelli AM, Bareggi R, Cataldi A, Cocco L (1993) The protein kinase inhibitor staurosporine induces morphological changes 
typical of apoptosis in MOLT-4 cells without concomitant DNA fragmentation. Biochem Biophys Res Commun 193:19-25.

Greenlund LJS, Deckwerth TL, Johnson EM Jr (1995) Superoxide dismutase delays neuronal apoptosis: a role for reactive oxygen species in programmed cell death. Neuron 14:303-315.

Hartley DM, Choi DW (1989) Delayed rescue of $N$-methyl-D-aspartate receptor-mediated neuronal injury in cortical culture. J Pharmacol Exp Ther 250:752-758.

He L, Poblenz A, Medrano CJ, Fox DA (2000) Lead and calcium produce rod photoreceptor cell apoptosis by opening the mitochondrial permeability transition pore. J Biol Chem 275:12175-12184.

Jiang S, Cai J, Wallace DC, Jones DP (1999) Cytochrome c-mediated apoptosis in cells lacking mitochondrial DNA. J Biol Chem 274:29905-29911.

Jordan J, Ghadge GD, Prehn JHM, Toth P, Roos RP, Miller RJ (1995) Expression of human $\mathrm{Cu} / \mathrm{Zn}$ superoxide dismutase inhibits the death of sympathetic neurons caused by withdrawal of nerve growth factor. Mol Pharmacol 47:1095-1100.

King MP, Attardi G (1989) Human cells lacking mtDNA: repopulation with exogenous mitochondria by complementation. Science 246:500-503.

Krippner A, Matsuno-Yagi A, Gottlieb RA, Babior BM (1996) Loss of function of cytochrome $\mathrm{c}$ in Jurkat cells undergoing Fas-mediated apoptosis. J Biol Chem 271:21629-21636.

Kroemer G, Dallaporta B, Resche-Rigon M (1998) The mitochondrial death/life regulator in apoptosis and necrosis. Annu Rev Physiol 60:619-642.

Krohn AJ, Preis E, Prehn JHM (1998) Staurosporine-induced apoptosis of cultured rat hippocampal neurons involves caspase-1-like proteases as upstream initiators and increased production of superoxide as a main downstream effector. J Neurosci 18:8186-8197.

Krohn AJ, Wahlbrink T, Prehn JHM (1999) Mitochondrial depolarization is not required for neuronal apoptosis. J Neurosci 19:7394-7404.

Lafon-Cazal M, Pietri S, Culcasi M, Bockaert J (1993) NMDA-dependent superoxide production and neurotoxicity. Nature 364:535-537.

Lankiewicz S, Luetjens CM, Bui NT, Krohn AJ, Poppe M, Cole GM, Saido TC, Prehn JHM (2000) Activation of calpain I converts excitotoxic neuron death into a caspase-independent cell death. J Biol Chem 275:17064-17071.

Li P, Nijhawan D, Budihardjo I, Srinivasula SM, Ahmad M, Alnemri ES, Wang X (1997) Cytochrome c and dATP-dependent formation of Apaf1/caspase-9 complex initiates an apoptotic protease cascade. Cell 91:479-489.

Liu X, Kim CN, Yang J, Jemmerson R, Wang X (1996) Induction of apoptotic program in cell-free extracts: requirement for dATP and cytochrome c. Cell 86:147-157.

Malis CD, Bonventre JV (1985) Mechanism for calcium potentiation of oxygen free radical injury to renal mitochondria. J Biol Chem 261:14201-14208.

Martinou I, Desagher S, Eskes R, Antonsson B, André E, Fakan S, Martinou J (1999) The release of cytochrome c from mitochondria during apoptosis of NGF-deprived sympathetic neurons is a reversible event. J Cell Biol 144:883-889.

Patel M, Day BJ (1999) Metalloporphyrin class of therapeutic catalytic antioxidants. Trends Pharmacol Sci 20:359-364.

Patel M, Day BJ, Crapo JD, Fridovich I, McNamara JO (1996) Requirement for superoxide in excitotoxic cell death. Neuron 16:345-355.

Peng TI, Greenamyre JT (1998) Priviliged access to mitochondria of calcium influx through $N$-methyl-D-aspartate receptors. Mol Pharmacol 53:974-980.
Peng TI, Jou MJ, Sheu SS, Greenamyre JT (1998) Visualization of NMDA receptor-induced mitochondrial calcium accumulation in striatal neurons. Exp Neurol 149:1-12.

Prehn JHM, Lippert K, Krieglstein J (1995) Are NMDA or AMPA/ kainate receptor antagonists more efficacious in the delayed treatment of excitotoxic neuronal injury? Eur J Pharmacol 13:179-189.

Reynolds IJ, Hastings TG (1995) Glutamate induces the production of reactive oxygen species in cultured forebrain neurons following NMDA receptor activation. J Neurosci 15:3318-3327.

Schulz JB, Weller M, Klockgether T (1996) Potassium deprivationinduced apoptosis of cerebellar granule neurons: a sequential requirement for new mRNA and protein synthesis, ICE-like protease activity, and reactive oxygen species. J Neurosci 16:4696-4706.

Sengpiel B, Preis E, Krieglstein J, Prehn JHM (1998) NMDA-induced superoxide production and neurotoxicity in cultured rat hippocampal neurons: role of mitochondria. Eur J Neurosci 10:1903-1910.

Siman R, Noszek JC, Kegerise C (1989) Calpain I activation is specifically related to excitatory amino acid induction of hippocampal damage. J Neurosci 9:1579-1590.

Smith LL, Rose MS, Wyatt I (1978) The pathology and biochemistry of paraquat. Ciba Found Symp 65:321-341.

Stefanis L, Park DS, Yun C, Yan I, Farinelli SE, Troy CM, Shelanski ML, Greene LA (1996) Induction of CPP32-like activity in PC12 cells by withdrawal of trophic support. J Biol Chem 271:30663-30671.

Stout AK, Raphael HM, Kanterewicz BI, Klann E, Reynolds IJ (1998) Glutamate-induced neuron death requires mitochondrial calcium uptake. Nat Neurosci 1:366-373.

Taylor J, Gatchalian CL, Keen G, Rubin LL (1997) Apoptosis in cerebellar granule neurons: involvement of interleukin-1 $\beta$ converting enzymelike proteases. J Neurochem 68:1598-1605.

Turrens JF, Boveris A (1980) Generation of superoxide anion by the $\mathrm{NADH}$ dehydrogenase of bovine heart mitochondria. Biochem $\mathrm{J}$ 191:421-427.

Tymianski M, Wallace MC, Spigelman I, Uni M, Carlen PL, Tator CH, Charlton MP (1993) Cell permeant $\mathrm{Ca}^{2+}$ chelators reduce early excitotoxic and ischemic neuronal injury in vitro and in vivo. Neuron 11:221-235.

Vaillant F, Nagley P (1995) Human cell mutants with very low mitochondrial DNA copy number $\left(\rho^{\mathrm{d}}\right)$. Hum Mol Genet 4:903-914.

Vinores SA, Herman MM, Katsetos CD, May EE, Frankfurter A (1994) Neuron-associated class III tubulin, tau and MAP2 in the D-283 Med cell line and in primary explants of human medulloblastoma. Histochem $\mathbf{J}$ 26:678-685.

Wadia JS, Chalmers-Redman RME, Ju WJH, Carlile GW, Phillips JL, Fraser AD, Tatton WG (1998) Mitochondrial membrane potential and nuclear changes in apoptosis caused by serum and nerve growth factor withdrawal: time course and modification by $(-)$-deprenyl. J Neurosci 18:932-947.

White RJ, Reynolds IJ (1995) Mitochondria and $\mathrm{Na}^{+} / \mathrm{Ca}^{2+}$ exchange buffer glutamate-induced calcium in cultured cortical neurons. J Neurosci 15:1318-1328.

White RJ, Reynolds IJ (1996) Mitochondrial depolarization in glutamatestimulated neurons: an early signal specific to excitotoxin exposure. J Neurosci 16:5688-5697.

Yu SP, Yeh C-H, Strasser U, Tian M, Choi DW (1999) NMDA receptormediated $\mathrm{K}^{+}$efflux and neuronal apoptosis. Science 284:336-339. 